\title{
Curcumin exerts a protective effect on murine knee chondrocytes treated with IL-1 $\beta$ through blocking the NF-кB/HIF-2 $\alpha$ signaling pathway
}

\author{
Pengzhen Wang ${ }^{1 \#}$, Yanchen Ye ${ }^{2,3 \#}$, Wei Yuan ${ }^{4}$, Yanping Tan ${ }^{5}$, Shaoheng Zhang ${ }^{6}$, Qingqi Meng ${ }^{1}$ \\ ${ }^{1}$ Guangzhou Institute of Traumatic Surgery, Guangzhou Red Cross Hospital, Jinan University, Guangzhou, China; ${ }^{2}$ Division of Vascular Surgery, \\ The First Affiliated Hospital, Sun Yat-sen University, Guangzhou, China; ${ }^{3}$ National-Guangdong Joint Engineering Laboratory for Diagnosis \\ and Treatment of Vascular Diseases, The First Affiliated Hospital, Sun Yat-sen University, Guangzhou, China; ${ }^{4}$ Department of General Surgery, \\ Guangzhou Red Cross Hospital, Jinan University, Guangzhou, China; ${ }^{5}$ Department of Neurology, Guangzhou Red Cross Hospital, Jinan University, \\ Guangzhou, China; ${ }^{6}$ Department of Cardiology, Guangzhou Red Cross Hospital, Jinan University, Guangzhou, China \\ Contributions: (I) Conception and design: Q Meng, S Zhang, P Wang, Y Ye; (II) Administrative support: Q Meng, S Zhang; (III) Provision of study \\ materials or patients: P Wang; (IV) Collection and assembly of data: W Yuan, Y Tan; (V) Data analysis and interpretation: P Wang, Y Ye; (VI) \\ Manuscript writing: All authors; (VII) Final approval of manuscript: All authors. \\ \#These authors contributed equally to this work. \\ Correspondence to: Dr. Qingqi Meng. Guangzhou Institute of Traumatic Surgery, Guangzhou Red Cross Hospital, Jinan University, 396 Tongfu \\ Zhong Road, Guangzhou 510220, China. Email: meng_qingqi@126.com; Dr. Shaoheng Zhang. Department of Cardiology, Guangzhou Red Cross \\ Hospital, Jinan University, 396 Tongfu Zhong Road, Guangzhou 510220, China. Email: shaohengzh67@163.com.
}

Background: Osteoarthritis (OA) is characterized by erosion and degradation of articular cartilage. This study assessed the effects of curcumin on mouse knee cartilage chondrocytes.

Methods: Chondrocytes were treated for 24 hours with interleukin IL-1 $\beta(10 \mathrm{ng} / \mathrm{mL})$ alone, or the combination of curcumin $(10,20$, and $50 \mu \mathrm{M})$ and IL-1 $\beta$. The proliferation, viability, and cytotoxicity of the chondrocytes were evaluated by the MTS assay. Expression of SOX9, AGG, Col2 $\alpha$, MMP9, ADAMTS5, COX2, iNOS, pI $\kappa \mathrm{B}-\alpha, \mathrm{pNF}-\kappa \mathrm{B}$, and hypoxia-inducible factor- $2 \alpha(\mathrm{HIF}-2 \alpha)$ were detected by western blotting or quantitative polymerase chain reaction (q-PCR). Nuclear translocation of NF- $\kappa \mathrm{B}$ and HIF-2 $\alpha$ were investigated by immunofluorescence and immunohistochemistry. In in vivo experiments, mice were subjected to destabilization of the medial meniscus (DMM) and given curcumin orally for 6 weeks. Cartilage integrity was evaluated by OARSI (Osteoarthritic Research Society International) scores.

Results: Curcumin significantly inhibited the IL-1 $\beta$-induced reduction of cell viability, degradation of ECM, and the expression of SOX9, Col2 $\alpha$, and AGG $(\mathrm{P}<0.01)$. Western blotting, immunofluorescence and immunohistochemistry experiments demonstrated that curcumin dramatically inhibited the activation of $\mathrm{NF}-\kappa \mathrm{B} / \mathrm{HIF}-2 \alpha$ in chondrocytes treated with $\mathrm{IL}-1 \beta(\mathrm{P}<0.01)$. The articular scores were significantly lower in the DMM-induced OA mice compared to OA mice treated with curcumin $(\mathrm{P}<0.01)$.

Conclusions: Curcumin may have the potential to inhibit OA development, partly through suppressing the activation of the NF- $\kappa \mathrm{B} / \mathrm{HIF}-2 \alpha$ pathway.

Keywords: Osteoarthritis (OA); curcumin; chondrocytes; NF-кB; hypoxia-inducible factor-2 $\alpha$ (HIF-2 $\alpha$ )

Submitted May 07, 2021. Accepted for publication Jun 09, 2021.

doi: 10.21037/atm-21-2701

View this article at: http://dx.doi.org/10.21037/atm-21-2701 


\section{Introduction}

Osteoarthritis (OA) is characterized by the gradual degradation of cartilage in the knee, and as such, causes extreme pain and disability in patients (1). OA ranked the $11^{\text {th }}$ most common cause of disability among nearly 300 diseases reported in the 2010 Global Burden of Disease Research (2). According to the Center for Disease Control (CDC), with an increase in the aging population, the number of patients with $\mathrm{OA}$ is expected to more than double by the year 2030 (3). However, the etiology of OA is complicated and remains unclear. Studies have suggested that inflammation degrades the extracellular matrix (ECM) and decreases chondrocyte activity, which subsequently triggers the catabolic abilities of chondrocytes and inhibits chondrocyte proliferation (4).

Interleukin-1 $\beta$ (IL-1 $\beta$ ) is a major proinflammatory cytokine and has been shown to be involved in the degradation and degeneration of articular cartilage (5). Accumulating evidence suggests that IL- $1 \beta$ stimulates chondrocytes to release proteolytic enzymes such as matrix metalloproteinases (MMPs), a disintegrin and metalloproteinase with thrombospondin motifs (ADAMTS), cyclooxygenase 2 (COX2), and nitric oxide (NO) (6). IL$1 \beta$ can also reduce cell viability, increase cell apoptosis, and promote ECM metabolic imbalance (7). Furthermore, IL- $1 \beta$ is excessively secreted in cartilage lesions and synovial fluids of OA patients $(8,9)$. Therefore, limiting the expression and secretion of IL- $1 \beta$ is a key target in the prevention and treatment of $\mathrm{OA}$.

Despite the high prevalence of OA, there is currently no effective treatment or cure $(10,11)$. Therefore, the development of novel drugs that are safe and effective for the management of $\mathrm{OA}$ is urgently needed. Curcumin and its derivatives are biologically active ingredients of the herb Curcuma longa $(12,13)$. Curcumin has been reported to be a potential inhibitor of the JNK (c-Jun N-terminal kinase) signaling pathway, and an activator of STAT in human and bovine chondrocytes, thereby protecting chondrocytes and cartilage from degradation $(14,15)$. Curcumin has also been shown to inhibit the apoptosis of rabbit articular chondrocytes induced by sodium nitroprusside (16) and increase human chondrocyte proliferation (17).

A relatively new report confirmed that curcumin could inhibit the PERK-eIF2 $\alpha$-CHOP axis of the ER stress response through the activation of SIRT1 in tertButyl hydroperoxide- (TBHP-) treated rat chondrocytes and ameliorated osteoarthritis development in vivo (18).
However, the relationship between curcumin and NF$\kappa \mathrm{B} /$ hypoxia-inducible factor- $2 \alpha$ (HIF- $2 \alpha$ ) pathway in chondrocytes has not been reported yet. HIF- $2 \alpha$ plays an important role in inflammation $(19,20)$. Its expression in chondrocytes is positively correlated with the progression of OA in mice and humans (11). HIF-2 $\alpha$ is encoded by EPAS1 (endothelial PAS domain protein 1) and is a key upstream transcript of matrix metallopeptidase 9 (MMP9) and ADAMTS5. HIF- $2 \alpha$ promoter analysis studies have demonstrated that nuclear factor NF- $\kappa$ B regulates HIF-2 $\alpha$ transcriptional activity, and the NF- $\kappa \mathrm{B} / \mathrm{HIF}-2 \alpha$ signaling pathway is tightly associated with the development of $\mathrm{OA}$ following articular cartilage damage (21).

Although it is known that curcumin has a protective effect on chondrocytes, the effects of curcumin on the NF$\kappa \mathrm{B} / \mathrm{HIF}-2 \alpha$ signaling pathway in chondrocytes remains unclear. Therefore, this study explored the effects of curcumin on the expression of chondrogenic genes and transcription factors in chondrocytes stimulated by IL- $1 \beta$. The regulatory mechanisms and pathways involved were also examined. This report provides a theoretical basis for the clinical applications of curcumin in OA patients.

We present the following article in accordance with the ARRIVE reporting checklist (available at http://dx.doi. org/10.21037/atm-21-2701).

\section{Methods}

\section{Chemicals}

Recombinant murine IL-1 $\beta$ was purchased from PeproTechCo., Ltd. (Soochow, China). Curcumin was obtained from BiorulerCo., Ltd. (Beijing, China). Stock solutions of curcumin were dissolved in dimethyl sulfoxide (DMSO; Sigma Co., St. Louis, USA) at room temperature and stored at $-20{ }^{\circ} \mathrm{C}$. The final concentration of DMSO used in the culture was $0.01 \%(\mathrm{v} / \mathrm{v})$, and the working concentrations of curcumin were 10,20 , and $50 \mu \mathrm{M}$.

\section{Isolation and culture of murine chondrocytes, induction of $O A$ in mice, and curcumin treatment}

All animal experiments conformed to the ethical requirements of the Guangzhou Red Cross Hospital, Guangzhou, China. A total of 40 C57BL/6 male mice (6 weeks old and weighing 20-25 g) were given free access to water and food and housed in a comfortable cage and room. The mice were kept for five days prior to 
destabilization of the medial meniscus (DMM) surgery and chondrocyte isolation.

This study was approved by the Research Ethics Committee of the Guangzhou Red Cross Hospital, Guangzhou, 510220, China (Approval No. 2019-010-01), in compliance with national or institutional guidelines for the care and use of animals. Chondrocytes were isolated from the mice and digested as previously described (22). Briefly, 10 mice were sacrificed using carbon dioxide gas $(28 \%$ chamber volume per minute) under general anesthesia and chondrocytes were immediately isolated. The knee cartilage was digested with collagenase I (C0130, Sigma-Aldrich) and collagenase D (11088858001, Roche Diagnostics) for 30 minutes at $37^{\circ} \mathrm{C}$. The isolated chondrocytes were seeded at a concentration of $5 \times 10^{5}$ cells $/ \mathrm{mL}$ onto $10-\mathrm{cm}$ diameter Petri dishes containing complete Dulbecco's Modified Eagle's medium (DMEM) supplemented with $10 \%(\mathrm{v} / \mathrm{v})$ fetal bovine serum (FBS) and $1 \%$ penicillin and streptomycin, and incubated at $37{ }^{\circ} \mathrm{C}$ and $5 \% \mathrm{CO}_{2}$. After three days, the cells had reached confluency and the chondrocytes were harvested for subsequent experiments.

For the surgery-induced OA model, the remaining 30 male mice were anesthetized using $10 \mathrm{mg} / \mathrm{kg}$ xylazine (X1126; Sigma-Aldrich) and $50 \mathrm{mg} / \mathrm{kg}$ ketamine (693561; Sigma-Aldrich) under sterile conditions. Destabilization of the medial meniscus (DMM) was performed on the right knee joints. In the sham operation group, the medial meniscus of the mice was visualized but not stripped. After surgery, mice in the curcumin-treated groups received oral administration of $50 \mathrm{mg} / \mathrm{kg}$ curcumin (BiorulerCo., Ltd.) dissolved in corn oil, once a day, for 6 weeks (23). Mice in the surgical vehicle control groups were given corn oil only.

\section{Cell viability assay}

The effects of curcumin on chondrocytes were assessed by the MTS assay. Mouse chondrocytes were cultured in 96-well plates $(4,000$ cells/well) and treated with various concentrations $(0,10,20,50$ and $100 \mu \mathrm{M})$ of curcumin with or without $10 \mathrm{ng} / \mathrm{mL}$ IL-1 $\beta$ (Sigma Co., St Louis, Mo) at $37^{\circ} \mathrm{C}$. After 24 hours, cells were incubated with $20 \mu \mathrm{L}$ MTS at $37{ }^{\circ} \mathrm{C}$ for 4 hours. Absorbance at a wavelength of $490 \mathrm{~nm}$ was detected using a microplate reader (Leica Microsystems, Germany).

\section{Alcian blue and Safranin $O$ staining of chondrocytes}

A $20 \mu \mathrm{L}$ suspension of chondrocytes was plated into 4-well plates at a density of $1 \times 10^{6}$ cells $/ \mathrm{mL}$ and incubated for 3 hours. Following cell adhesion, $0.5 \mathrm{~mL}$ of fresh complete DMEM containing curcumin alone $(10,20$, and $50 \mu \mathrm{M})$, or curcumin $(10,20$ and $50 \mu M)$ combined with IL-1 $\beta(10 \mathrm{ng} / \mathrm{mL})$ was added to the cells. After 14 days, cells were fixed for 20 minutes with $0.5 \mathrm{~mL} 10 \%$ neutral buffered formalin. Cells were then stained with $0.5 \mathrm{~mL} 1 \%$ Alcian blue and $1 \%$ Safranin O for 30 minutes at room temperature. After washing with $1 \times$ phosphate buffered saline (PBS), images of the stained cell masses were obtained using a scanner.

\section{Immunofluorescence microscopy and capture of representative brightfield images}

Chondrocytes $\left(1 \times 10^{4}\right.$ cells $\left./ \mathrm{mL}\right)$ were grown in 6-well plates containing glass slides and cultured with complete DMEM containing curcumin alone (10, 20 and $50 \mu \mathrm{M})$ or curcumin $(10,20$ and $50 \mu \mathrm{M})$ combined with IL-1 $\beta(10 \mathrm{ng} / \mathrm{mL})$. The representative brightfield images of chondrocytes were captured under an inverted phase contrast microscope (Olympus; CKX41-A32PH). Cells were fixed with 90\% ethanol for 30 minutes. After blocking by $5 \%$ bovine serum albumin (BSA) for an hour, chondrocytes were incubated with primary antibodies against NF- $\kappa \mathrm{B}(1: 200 ; 8242$; CST) and HIF-2 $\alpha\left(1: 1,000\right.$; D6T8V; CST) at $4{ }^{\circ} \mathrm{C}$ overnight. Thereafter, cells were incubated with the secondary fluorescein-conjugated goat anti-rabbit antibody (1:200; ZF0311; OriGene Technologies, Maryland, USA) at room temperature for 1 hour. Images of the stained cells were visualized and captured using a fluorescence microscope (AXIO Vert.A1; 400× magnification).

\section{Western blotting}

Chondrocytes $\left(2 \times 10^{5}\right.$ cells/well $)$ were cultured in 6-well plates, and treated as described for the immunofluorescence studies. Cells were lysed and protein concentrations were determined by the BCA method. Proteins ( $20 \mu \mathrm{g} / \mathrm{lane})$ were separated by $10 \%$ SDS-PAGE (sodium dodecyl sulphatepolyacrylamide gel electrophoresis) and blotted onto PVDF (polyvinylidene fluoride) membranes (Merck). The membranes were blocked with $5 \%$ bovine serum albumin (BSA) for 1 hour at room temperature, and the proteins were sequentially probed with the following primary antibodies overnight at $4{ }^{\circ} \mathrm{C}$ : $\operatorname{SOX} 9(1: 1,000 ; 82630$; CST), NF-кB (1:1,000; 8242; CST), phosphorylated NF$\kappa \mathrm{B}(\mathrm{p} \mathrm{NF}-\kappa \mathrm{B} ; 1: 1,000 ; 93 \mathrm{H} 1$; CST), inhibitor of nuclear factor kappa B (IкB; 1:100; 44D4; CST), pIкB (1:1,000; 
Table 1 Sequences of primers used for gene amplification

\begin{tabular}{lcc}
\hline Genes & Forward & Reverse \\
\hline GAPDH & 5'-ATTGTGCACCGCAAATGCTT-3' & 5'-ACCACAGCACGATTGTCGAT-3' \\
SOX9 & 5'-GTGCAAGCTGGCAAAGTTGA-3' & 5'-TGCTCAGTTCACCGATGTCC-3' \\
Col2 $\alpha$ & 5'-GGTGAGCCATGATCCGCC -3' & 5'-TGGCCCTAATTTTCGGGCATC-3' \\
AGG & 5'-CGTTGCAGACCAGGAGCAAT-3' & 5'-CTCGGTCATGAAAGTGGCG'-3' \\
MMP9 & 5'-GTACTCGACCTGTACCAGCG-3' \\
iNOS & 5'-GCCCAGCCAGCCCAAC-3' & 5'-AGAAGCCCCACTTCTTGTCG-3' \\
ADAMTS5 & 5'-GCAGCTTGTCCAGGGATTCT-3' \\
COX2 & 5'-AAGAGGAGGAGGAGGAGGAGGAG-3' \\
\hline
\end{tabular}

14D4; CST), HIF-2 $\alpha$ (1:1,000; D6T8V; CST), MMP9 (1:1,000; 13667; CST), ADAMTS5 (1:1,000; PAB26036; AmyJet Scientific), inducible nitric oxide synthase (iNOS; 1:200; 13120S; CST), COX2 (1:200; BA3708; Boster), and glyceraldehyde 3-phosphate dehydrogenase (GAPDH; 1:1,000;5174; CST).Membrane were then incubated with an anti-rabbit/mouse IgGHRP-linked antibody $(1: 3,000 ; 7074 / 7076$; CST). Blots were determined using a chemiluminescence kit (Thermo Fisher Scientific, USA) and the images were captured by the ChemiDoc XRS Imaging System (Bio-Rad) and analyzed using Image Lab 5.2.1 software.

\section{Real time quantitative-PCR(q-PCR)}

Cells were treated as for the western blotting experiments described above. Total RNA was extracted from chondrocytes using TRIzol reagent (Thermo Fisher Scientific). Total mRNA $(1 \mu \mathrm{g})$ was used to synthesize the cDNA in a $20 \mu \mathrm{L}$ reaction using the PrimeScript RT Master Mix kit (RR036A, TaKaRa). TB Green Premix ExTaq II (RR066A, TaKaRa) was used to detect the mRNA of all genes in the qTOWER 2.2 real time PCR system (Analytik Jena, German). Primer sequences used were shown in Table 1 . The $2^{-\Delta \Delta C \mathrm{t}}$ method was used to analyze the expression of the genes, with GAPDH as the internal control (24).

\section{Histologic evaluation and immunobistochemical analysis}

This study was approved by the Research Ethics Committee of the Guangzhou Red Cross Hospital, Guangzhou, 510220, China (Approval No. 2019-010-01), in compliance with national or institutional guidelines for the care and use of animals. DMM or sham operations were performed on mice and after 6 weeks with or without curcumin treatment, mice were euthanized and the knee joints were harvested. Serial sections from the knee femur at a thickness of $5 \mu \mathrm{m}$ were used for Safranin $\mathrm{O} /$ fast green (SO) staining and immunohistochemical analysis. For immunohistochemistry, the goat two-step detection kit was used to detect the antigens according to the manufacturer's instructions (PV8000, ZSGB-BIO). Slides were incubated with either rabbit polyclonal anti-NF-кB antibody (1:200; 8242; Cell Signal Technology) or rabbit polyclonal anti-HIF- $2 \alpha$ antibody (1:200; D6T8V; CST) together with rabbit polyclonal anti-proliferating cell nuclear antibody (PCNA) antibody $\left(1: 50 ; 13110\right.$; CST) overnight at $4{ }^{\circ} \mathrm{C}$. Slides were then incubated with a horseradish peroxidase (HRP)-conjugated secondary antibody for 1 hour at room temperature. The reaction was visualized following incubation with $\mathrm{DAB}$ (3,3'-diaminobenzidine) solution for 5 minutes at room temperature. Photos were obtained with an inverted phase contrast microscope (Olympus; CKX41-A32PH). The adapted histological parameters originating from the International Cartilage Repair Society (ICRS) II included the following: (I) matrix staining; (II) subchondral bone; and (III) overall assessment. The cartilage sections were scored by three blinded readers according to the ICRS II parameters and criteria (25).

\section{Statistical analysis}

Experiments were performed in sets of triplicates of more and the data is presented as means \pm standard deviation (SD) and analyzed by one-way analysis of variance (ANOVA). A $\mathrm{P}$ value $<0.05$ was considered statistically significant. 
A<smiles>COc1cc(/C=C/C(=O)/C=C(O)/C=C/c2ccc(O)c(O)c2)ccc1O</smiles>

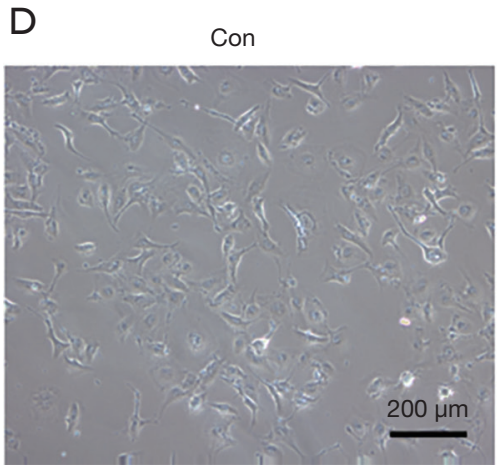

B

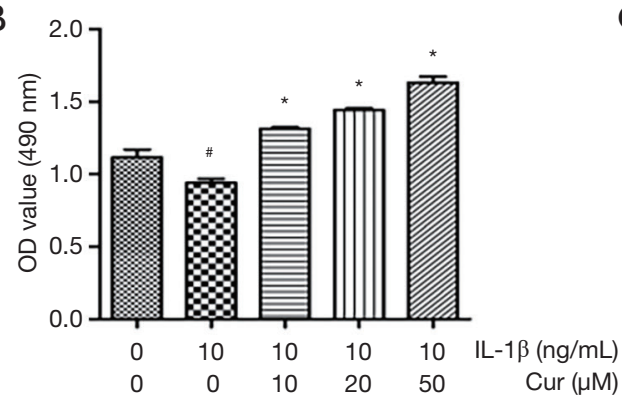

E

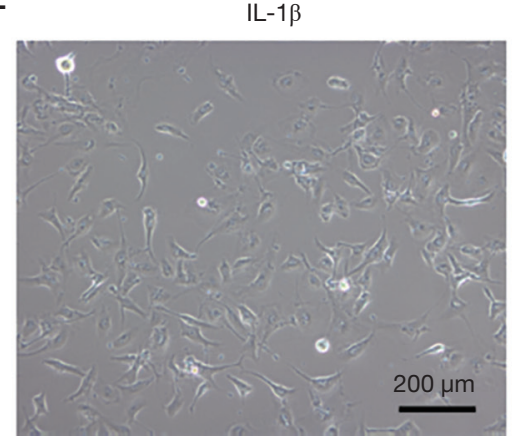

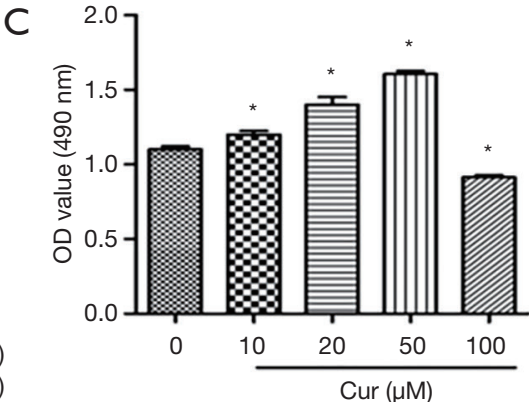

$\mathrm{F}$

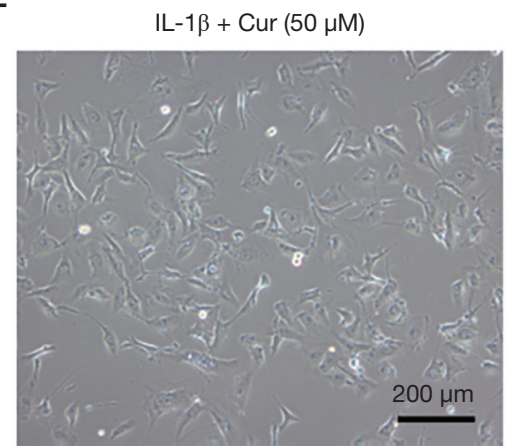

Figure 1 The effects of curcumin on mouse chondrocyte viability and cell morphology. (A) The chemical formula of curcumin. (B) MTS assays were used to analyze the viability of chondrocytes cultured in 10, 20, 50, and $100 \mu \mathrm{M}$ curcumin for 24 hours. (C) Absorbance at $490 \mathrm{~nm}$

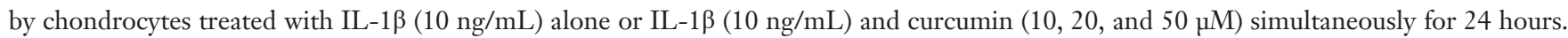
$(\mathrm{D}, \mathrm{E}, \mathrm{F})$ Cell morphology of the murine knee chondrocyte treated with or without curcumin $(50 \mu \mathrm{M})$ in the presence of IL-1 $\beta(10 \mathrm{ng} / \mathrm{mL})$.

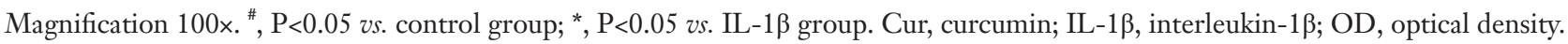

\section{Results}

\section{The effects of curcumin on chondrocyte viability and cell morphology}

The effects of curcumin on the viability of chondrocytes was evaluated by the MTS assay (Figure 1A). Chondrocytes were treated with increasing concentrations of curcumin $(10,20$, 50 , and $100 \mu \mathrm{M}$ ) for 24 hours. The viability of chondrocytes was significantly increased by curcumin at doses of 10, 20, and $50 \mu \mathrm{M}$ compared with control cells $(\mathrm{P}<0.05$; Figure $1 B)$. However, chondrocyte viability was obviously inhibited by curcumin at $100 \mu \mathrm{M}$ concentration $(\mathrm{P}<0.05)$. IL-1 $\beta$ $(10 \mathrm{ng} / \mathrm{mL})$ significantly reduced the viability of chondrocytes (Figure 1C). Interestingly, curcumin dosedependently $(10,20$, and $50 \mu \mathrm{M})$ attenuated the IL-1 $\beta$ induced decrease in cell viability $(\mathrm{P}<0.05$; Figure $1 C)$. Figure $1 D, E, F$ indicated that IL-1 $\beta$ and curcumin $(50 \mu \mathrm{M})$ did not exert an effect on the cell morphology. This was consistent with the observations in chondrocytes treated with curcumin alone. Therefore, 10, 20, and $50 \mu \mathrm{M}$ curcumin were chosen for subsequent experiments.

\section{The effects of curcumin on chondrocyte-specific genes and chondrocyte catabolism genes}

Safranin $\mathrm{O}$ and Alcian blue staining are classic methods for measuring the amount of aggrecan (AGG) secreted from chondrocytes (16). Compared with untreated chondrocytes, IL-1 $\beta$ significantly reduced the secretion of AGG from chondrocytes $(\mathrm{P}<0.05$; Figure $2 A)$. Furthermore, curcumin $(10,20$, and $50 \mu \mathrm{M})$ was able to restore the secretion of AGG in chondrocytes treated with IL-1 $\beta(\mathrm{P}<0.05)$.

The mRNA expression of AGG, collagen Col2 $\alpha$, and SOX9 was significantly downregulated in chondrocytes treated with IL- $1 \beta$ compared with that of control cells $(\mathrm{P}<0.05)$. Curcumin obviously attenuated the decreased expression of AGG, Col2 $\alpha$, and SOX9 induced by IL$1 \beta(\mathrm{P}<0.05)$. In addition, the protein expression of SOX9 was also significantly downregulated in IL-1 $\beta$-treated chondrocytes compared to control cells $(\mathrm{P}<0.05)$, and this 


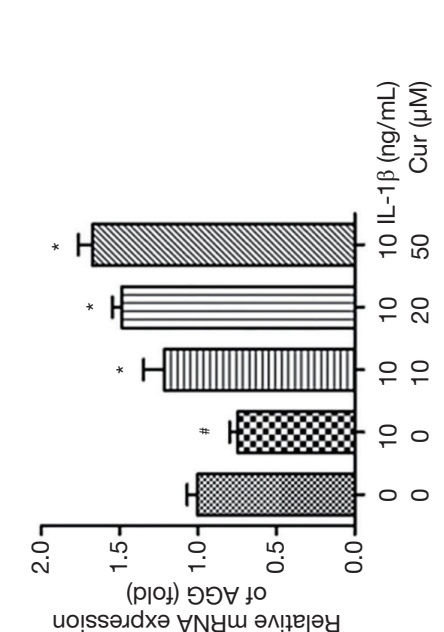

๓

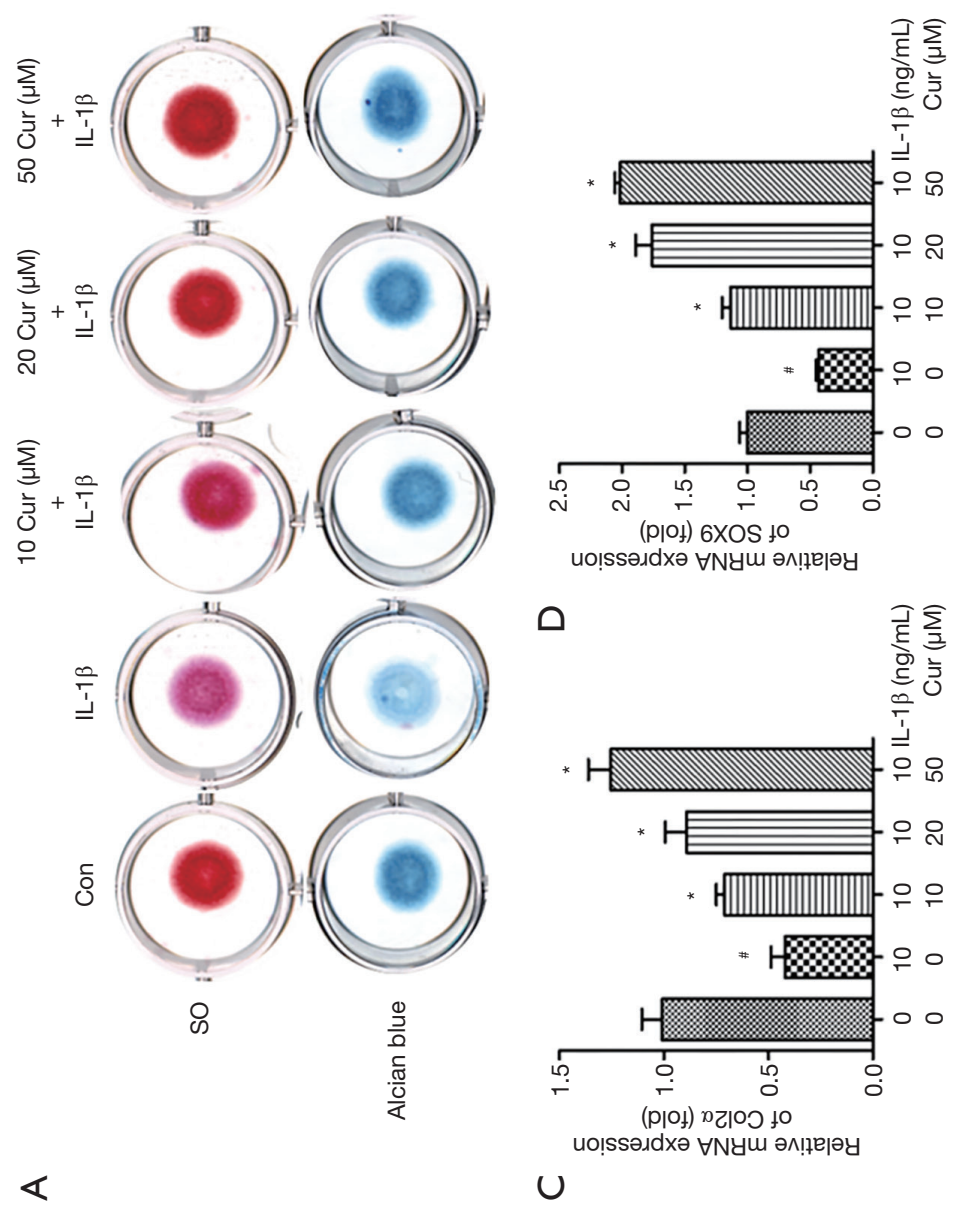

要

工

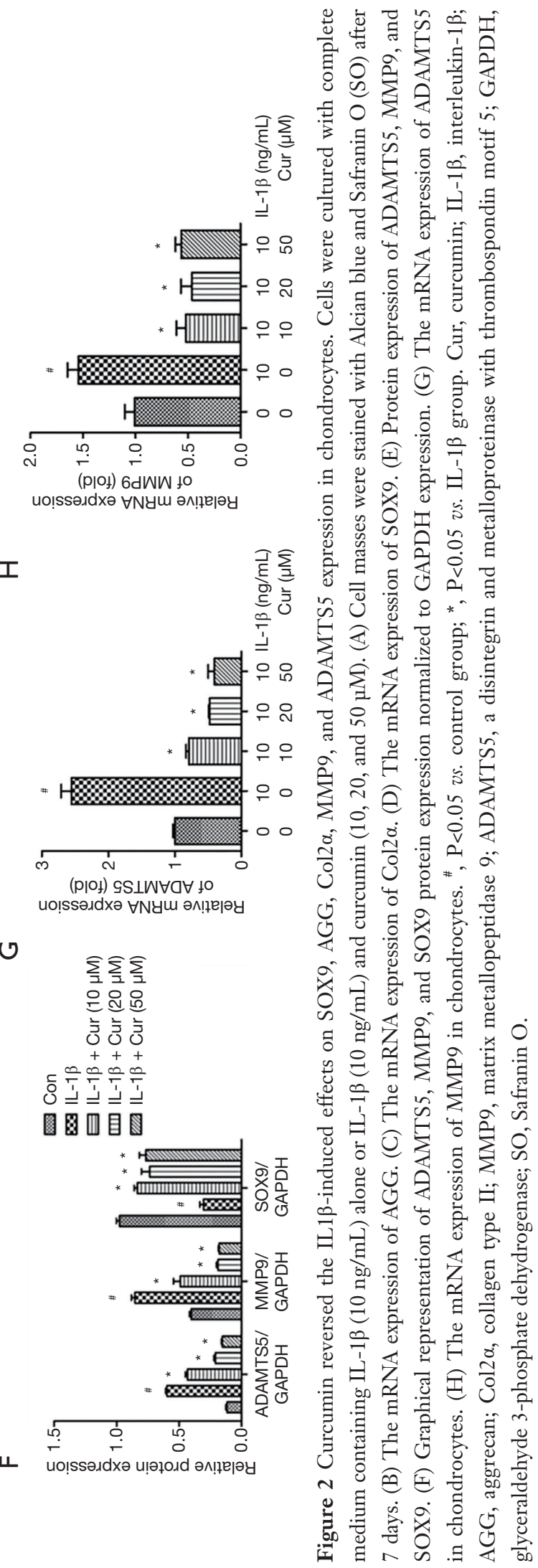



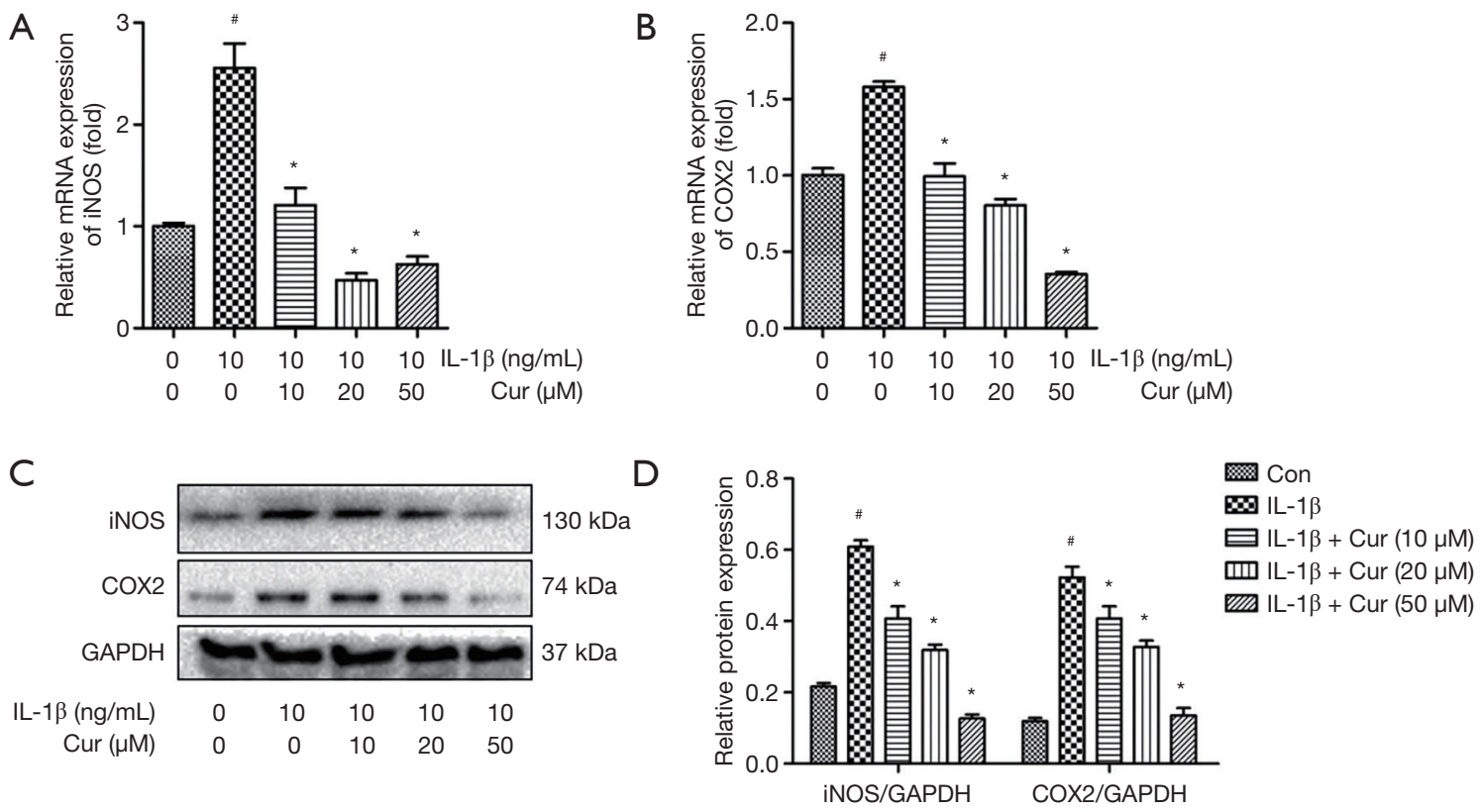

Figure 3 Curcumin suppressed the IL-1 $\beta$-induced overexpression of iNOS and COX2 in chondrocytes. Chondrocytes were cultured with complete medium containing IL-1 $\beta(10 \mathrm{ng} / \mathrm{mL})$ alone or IL-1 $\beta(10 \mathrm{ng} / \mathrm{mL})$ and curcumin $(10,20$, and $50 \mu \mathrm{M})$ for $24 \mathrm{hours}$. (A) The mRNA expression of iNOS in chondrocytes. (B) The mRNA expression of COX2 in chondrocytes. (C) Protein expression of iNOS and COX2 in chondrocytes. (D) Graphical representation of iNOS and COX2 protein expression normalized to GAPDH expression. * $\mathrm{P}<0.05$ vs. control group; *, $\mathrm{P}<0.05$ vs. IL-1 $\beta$ group. Cur, curcumin; IL-1 $\beta$, interleukin-1 $\beta$; iNOS, inducible nitric oxide synthase; COX2, cyclooxygenase 2; GAPDH, glyceraldehyde 3-phosphate dehydrogenase.

decrease was significantly ameliorated by curcumin $(\mathrm{P}<0.05$; Figure $2 B, C, D, E, F)$. IL-1 $\beta$ significantly elevated the mRNA and protein expression of ADAMTS5 and MMP9 compared to control cells (Figure $2 E, F, G, H$ ), and this sharp increase was significantly inhibited by curcumin intervention in a dose-dependent manner $(\mathrm{P}<0.05$; Figure 2B, $C, D, E, F)$.

\section{The effects of curcumin on $i N O S$ and COX2 expression in IL-1B-treated chondrocytes}

Chondrocytes treated with IL-1 $\beta$ showed marked upregulation of iNOS and COX 2 mRNA and protein expression compared to control chondrocytes $(\mathrm{P}<0.01$; Figure $3 A, B, C, D)$. By contrast, curcumin $(10,20$, and $50 \mu M)$ dose-dependently reversed the increased mRNA expression of iNOS and COX2 in chondrocytes stimulated with IL- $1 \beta$ $(\mathrm{P}<0.01)$.

\section{The effects of curcumin on $N F-\kappa B / H I F-2 \alpha$ signal pathway

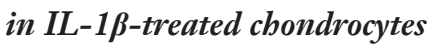

To understand the protective mechanisms of curcumin on chondrocytes, the NF- $\mathrm{BB} / \mathrm{HIF}-2$ asignaling pathway was examined. Compared to untreated chondrocytes, the ratios of pNF- $\kappa \mathrm{B} / \mathrm{NF}-\kappa \mathrm{B}$, pI $\kappa \mathrm{B}-\alpha / \mathrm{I} \kappa \mathrm{B}-\alpha$, and HIF- $2 \alpha / \mathrm{GAPDH}$ in chondrocytes treated by IL-1 $\beta$ were significantly increased $(\mathrm{P}<0.01$; Figure $4 A, B)$. Curcumin exerted a dramatic inhibitory effect on IL-1 $\beta$-induced phosphorylation of $\mathrm{NF}-\kappa \mathrm{B}$ and $\mathrm{I} \kappa \mathrm{B}-\alpha$, and expression of HIF- $2 \alpha(\mathrm{P}<0.01)$. Immunofluorescence staining demonstrated that in control chondrocytes, NF- $\mathrm{KB}$ was mainly expressed in the cytoplasm. In contrast, IL- $1 \beta$ stimulation increased nuclear staining of NF- $\kappa \mathrm{B}$ and HIF- $2 \alpha$, while curcumin significantly inhibited IL-1 $\beta$-induced nuclear expression of NF- $\kappa \mathrm{B}$ and HIF-2 $\alpha$ (Figure $4 C, D$ ). Taken together, these findings suggested that curcumin inhibited the IL- $1 \beta$-induced nuclear translocation of NF- $\mathrm{NB}$ and $\mathrm{HIF}-2 \alpha$.

\section{Curcumin reduced the cartilage degradation in DMM-

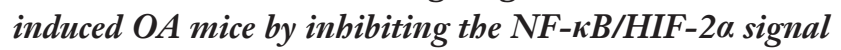 patbway}

The in vivo effects of curcumin on the structural features of articular cartilage were examined using a DMM-induced 

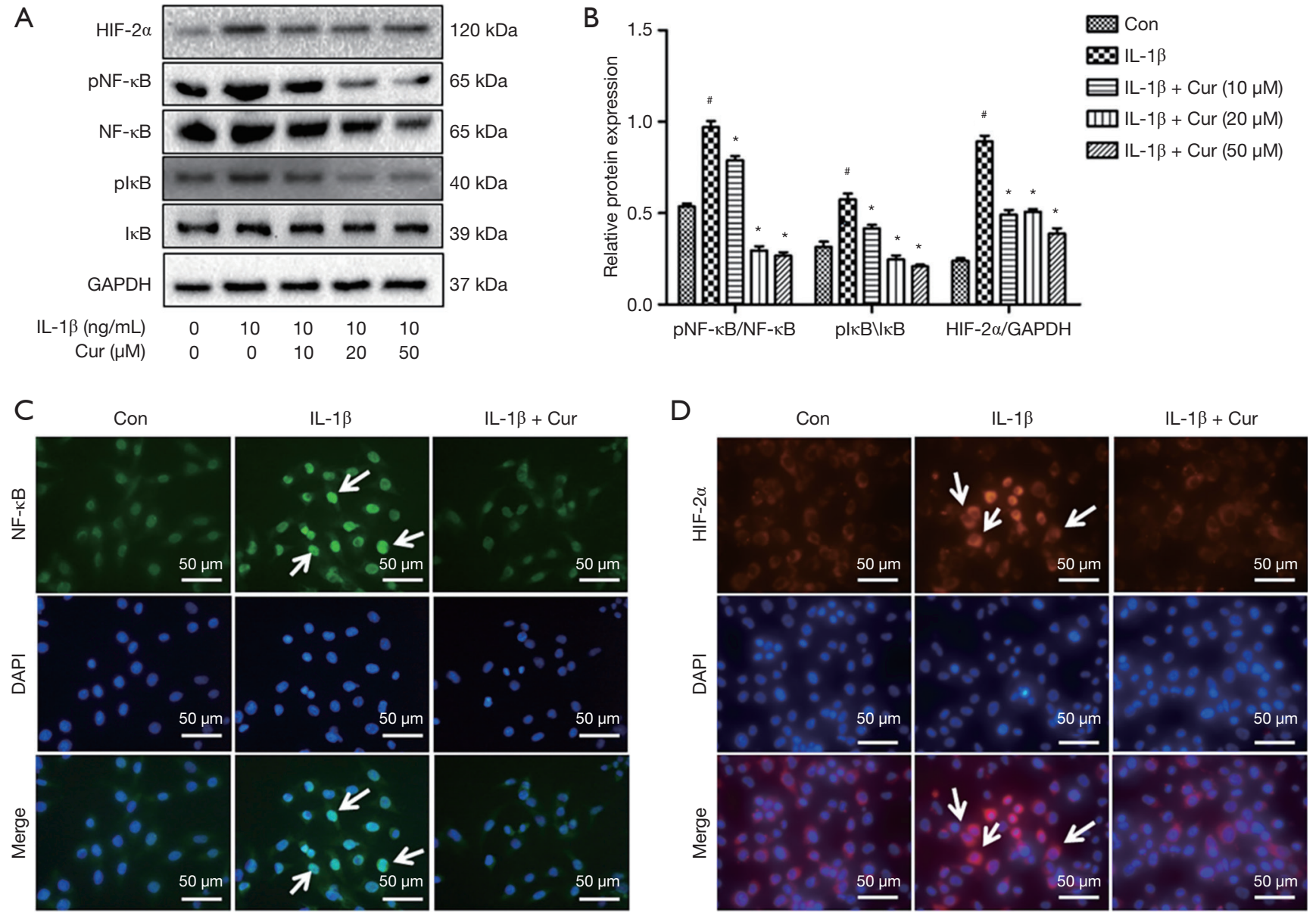

Figure 4 The effects of curcumin on IL- $1 \beta$-induced NF- $\kappa$ B/HIF- $2 \alpha$ activation in mouse chondrocytes. (A) A representative Western

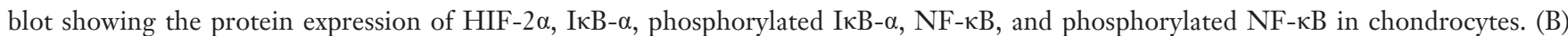
A graphical representation of HIF-2 $\alpha$, I $\kappa-\alpha$, phosphorylated I $\kappa$ B- $\alpha, \mathrm{NF}-\kappa \mathrm{B}$, and phosphorylated NF- $\kappa \mathrm{B}$ protein expression normalized to GAPDH expression. (C) Immunofluorescence staining of NF- $\kappa$ B expression in the nucleus of chondrocytes. (D) Immunofluorescence staining of HIF- $2 \alpha$ in the nucleus of chondrocytes. White arrows indicate NF- $\kappa \mathrm{B}$ and HIF-2 $\alpha$ positive cells in Figure $4 C$ and $4 D$. Magnification 400×. ", $\mathrm{P}<0.05$ vs. control group; *, $\mathrm{P}<0.05$ vs. IL-1 $\beta$ group. Cur, curcumin; IL-1 $\beta$, interleukin- $1 \beta$; HIF-2 $\alpha$, hypoxia-inducible

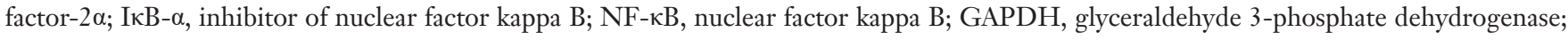
Con, control; DAPI, 4',6-diamidino-2-phenylindole. White arrows indicate positive cells.

OA mouse model. Mice that underwent DMM surgery exhibited OA pathology characterized by reduced Safranin $\mathrm{O}$ staining and a rough articular surface. DMM mice treated with curcumin showed increased Safranin $\mathrm{O}$ staining and an increase in the rough articular surface compared with sham groups and $\mathrm{OA}$ groups (Figure 5).

The matrix staining and articular surface scores were significantly lower in the OA group compared to the sham operation group $(\mathrm{P}<0.01)$, indicating that the $\mathrm{DMM}$ models were successfully established. Quantitative analysis revealed that cartilage matrix staining (Safranin O positive stained areas) was notably higher in curcumin-treated DMM mice compared to untreated DMM mice $(\mathrm{P}<0.05$; Figure $5 A, B)$. In addition, the ICRS II score of the overall assessment was obviously higher in curcumin-treated DMM mice compared to the OA mice $(\mathrm{P}<0.05)$. Immunohistochemistry and quantitation analysis showed that mice in the curcumin treatment group displayed an obvious decrease in NF- $\mathrm{KB}$ positive cells and HIF- $2 \alpha$ positive cells compared to mice in the OA group. There was an increase in the number of PCNA immuno-reactive cells in the joint region in the curcumin treatment group compared with OA group 
A

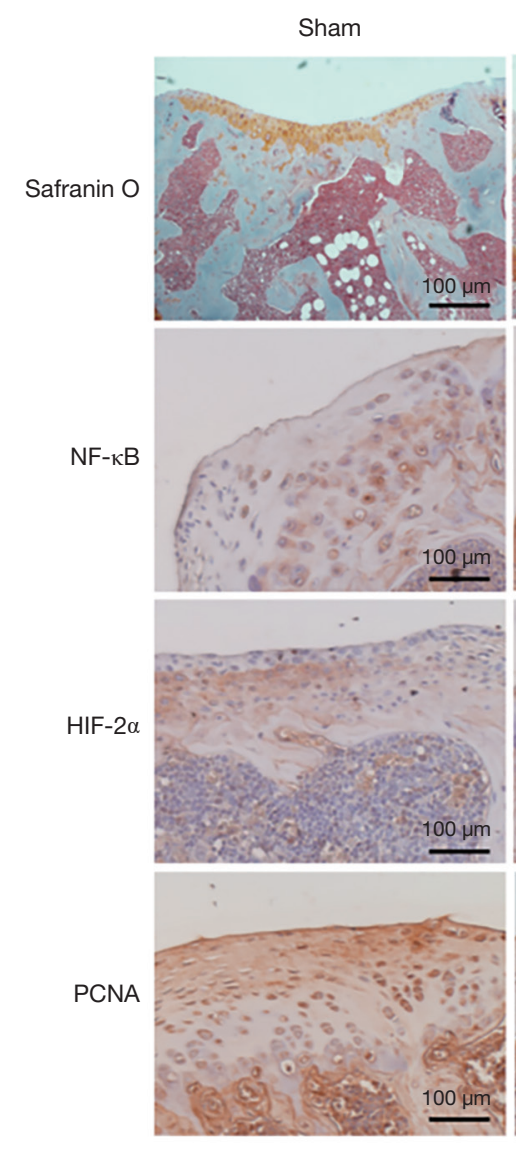

B

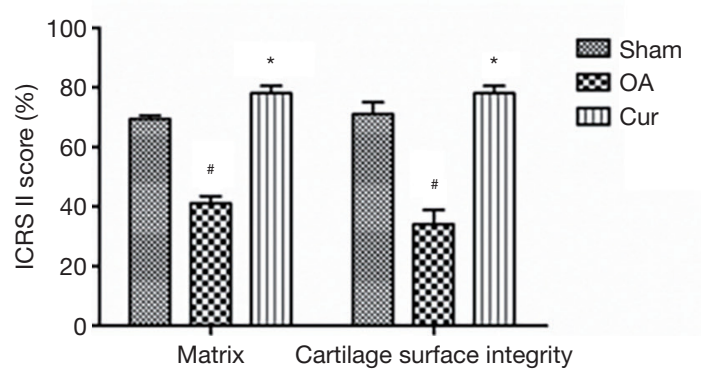

$\mathrm{OA}$
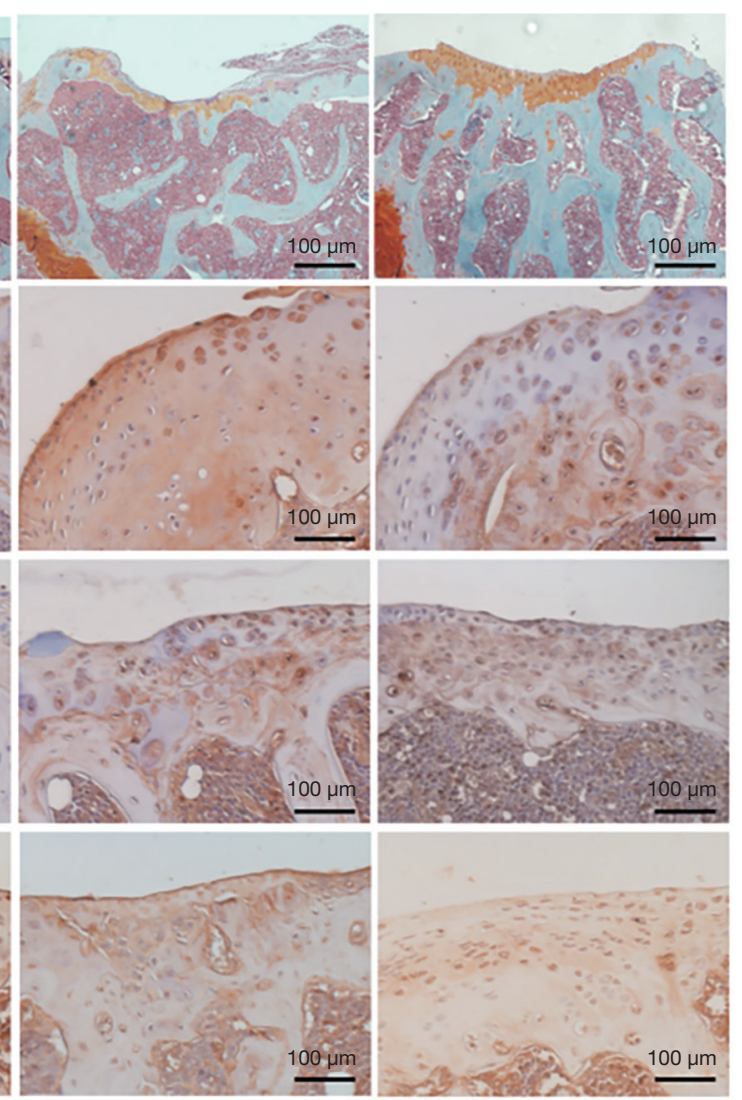

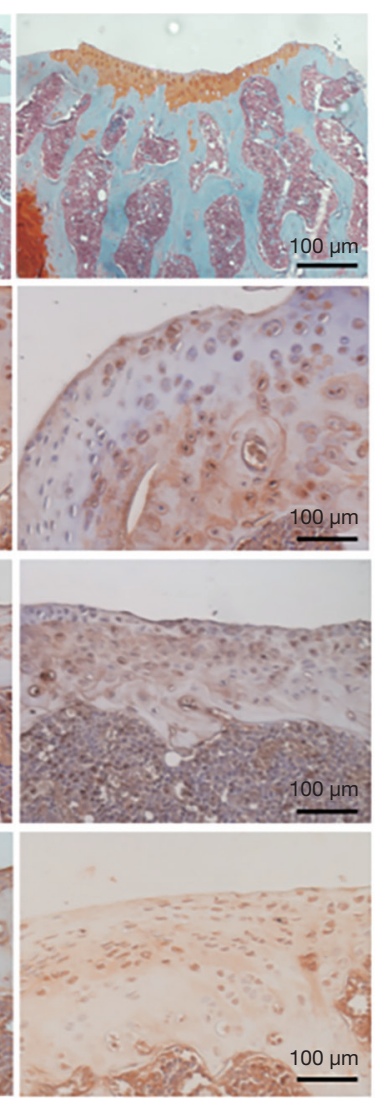

Cur
C

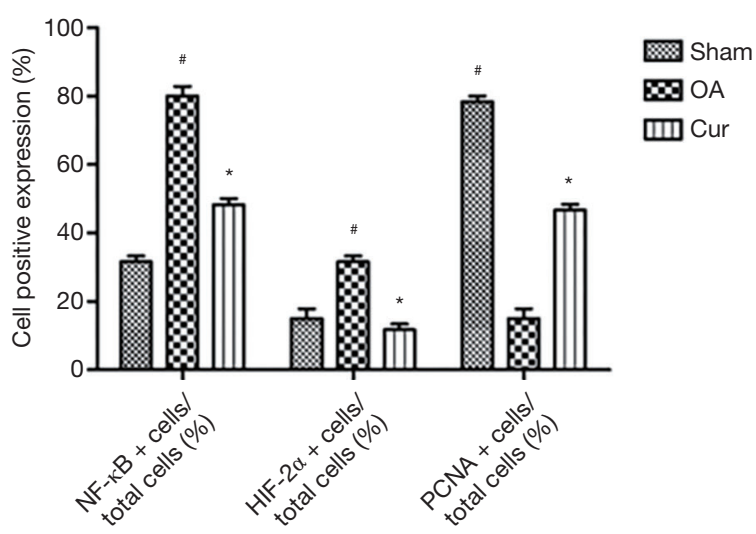

Figure 5 Curcumin suppressed the NF- $\mathrm{kB} / \mathrm{HIF}-2 \alpha$ pathway in chondrocytes in vivo. (A) Safranin $\mathrm{O}$ staining of the articular cartilage from the sham operation mice (Sham), the DMM-induced OA mice (OA, and the curcumin-treated OA mice (Cur). Immunostaining for NF- $\mathrm{KB}$, HIF-2 $\alpha$, and PCNA in mouse chondrocytes. (B) Quantitation of the ICRS II cartilage repair score at 6 weeks after curcumin treatment. (C)

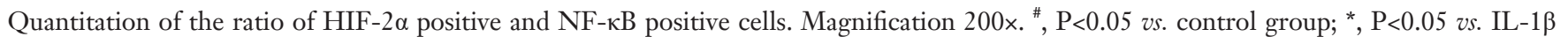
group. Cur, curcumin; IL-1 $\beta$, interleukin-1 $\beta$; HIF-2 $\alpha$, hypoxia-inducible factor-2 $\alpha$; NF-кB, nuclear factor kappa B; PCNA, proliferating cell nuclear antigen; DMM, destabilized medial meniscus; OA, osteoarthritis; ICRS II, International Cartilage Repair Society II. 
(Figure $5 A, C$ ). This was in agreement with the positive effects of curcumin on the proliferation of chondrocytes (Figure 1B). These results suggested that curcumin treatment improved the integrity of the articular cartilage, partially by suppressing the NF- $\mathrm{\kappa B} / \mathrm{HIF}-2 \alpha$ signaling pathway.

\section{Discussion}

Accumulating studies have demonstrated that inflammation in the chondrocytes and cartilage, mediated by IL$1 \beta$ or TNF- $\alpha$, plays a vital role in the development and progression of OA (26). Recently, Chinese medicine extracts have shown increasing potential as treatments for OA due to their anti-inflammatory properties and fewer side effects $(27,28)$. Curcumin has been shown to inhibit apoptosis in IL-1 $\beta$-stimulated human chondrocytes in vitro (29). However, the mechanisms by which curcumin protects cartilage from degradation and the inflammatory pathways involved remain little understood. This current investigation explored the effects of curcumin on IL-1 $\beta$ induced inflammation in vitro using isolated chondrocytes and in vivo using a DMM-induced OA mouse model.

In the MTS assays, curcumin at concentrations of 10 , 20 , and $50 \mu \mathrm{M}$ increased chondrocyte viability, however, at a concentration of $100 \mu \mathrm{M}$, curcumin showed a strong inhibitory effect on chondrocyte activity. Therefore, the effects of curcumin on chondrocyte activity were dosedependent, low concentrations of curcumin $(10,20$, and $50 \mu \mathrm{M})$ increased chondrocyte viability and high concentration $(100 \mu \mathrm{M})$ inhibited chondrocyte viability. Thus, the three gradient concentrations of 10, 20, and $50 \mu \mathrm{M}$ curcumin were used in all subsequent experiments. In the acquisition and analysis of representative bright field images, the results that IL- $1 \beta$ and curcumin did not affect cell morphology were confirmed.

In the present study, chondrocytes were stimulated with $10 \mathrm{ng} / \mathrm{mL}$ IL- $1 \beta$, which is an established method to mimic chondrocyte inflammation in vitro (7). Chondrocyte activity was decreased after treatment with IL-1 $\beta$, however, curcumin significantly reversed the trend and promoted the activity of chondrocytes. Furthermore, immunohistochemical results of articular cartilage demonstrated that compared with the sham group and the DMM-induced OA group, curcumin dramatically increased the numbers of PCNA positive cells. Since PCNA is a known molecular marker for proliferation (30), this indicated that curcumin significantly increased chondrocyte activity in vivo. These conclusions are consistent with those reported in the literature (31).

Safranin $\mathrm{O}$ and Alcian blue staining are classic methods for detecting the ECM component, AGG (16). Safranin O and Alcian blue staining indicated that IL-1 $\beta(10 \mathrm{ng} / \mathrm{mL})$ downregulated the secretion of AGG in chondrocytes. Curcumin reversed the down-regulated expression of SOX9, AGG, and Col $2 \alpha$ in chondrocytes induced by IL- $1 \beta$. The main components of chondrocyte ECM are AGG and Col2 $\alpha$, both of which are target proteins of SOX9. SOX9 is an important transcription factor for chondrocytes. In addition, the present study showed that oral administration of curcumin in mice significantly improved the ECM staining of the articular cartilage, indicating that curcumin may be beneficial in the treatment of joints in OA.

IL- $1 \beta$ can induce the expression of iNOS and COX2, both of which have been shown to play a crucial role in in the pathophysiology of OA (32). Furthermore, NO and prostaglandin E2 (PGE2) can be secreted by OA cartilage and both are overexpressed in OA joint synovial fluid. Interestingly, $\mathrm{NO}$ is generated through iNOS, while PGE2 is produced by COX2 (33). An increasing number of reports have suggested that inhibiting the production of these inflammatory mediators may attenuate the progression of OA (34). For example, curcumin and the lecithin complex have been shown to exert a chondroprotective effect on human chondrocytes via inhibiting COX2 and iNOS expression (35). In this study, the expression of iNOS and COX 2 in mouse chondrocytes treated with IL- $1 \beta$ was upregulated, but this trend was reversed with the addition of curcumin, which is consistent with the literature. MMPs and ADAMTSs serve as key players in the degradation of ECM components, contributing to the destruction of articular cartilage (36). Curcumin treatment has been previously demonstrated to inhibit MMP9 and ADAMTS5 in a rat OA model, which was further confirmed in IL-1 $\beta$ injured chondrocytes (37). This current study demonstrated that curcumin obviously prevented the IL- $1 \beta$-induced MMP9 and ADAMTS5 expression at the mRNA and protein levels in mouse chondrocytes.

$\mathrm{NF}-\kappa \mathrm{B}$ signaling pathways are extremely critical for the initiation of inflammation that is involved in the pathogenesis of OA (38). Normally, NF- $\mathrm{kB}$ is present in the cytoplasm as an inactive transcription factor associated with I $\kappa$, an inhibitory protein (39). When stimulated by IL-1 $\beta$ or trauma, the I $\mathrm{B}$ protein is phosphorylated and released from the NF- $\mathrm{BB}$ complex, and nuclear translocation of $\mathrm{NF}-\kappa \mathrm{B}$ resulted in the transactivation of downstream 
target genes (40). The activity of the NF- $\kappa \mathrm{B}$ signaling pathway, along with other factors upstream of HIF- $2 \alpha$, is closely related with the occurrence of OA (41). HIF- $2 \alpha$ is a catabolic transcription factor in the osteoarthritic process. It can directly induce the expression of genes encoding catabolic factors, including MMP9 and ADAMTS5, in chondrocytes (42). Intra-articular administration of BMS345541 , a highly selective inhibitor of catalytic subunits for I $\mathrm{KB}$, has been shown to suppress the development of OA by downregulating signaling through the NF- $\kappa \mathrm{B} / \mathrm{HIF}-$ $2 \alpha$ axis (21). The results in this present report showed that curcumin could block the expression of NF- $\kappa \mathrm{B} / \mathrm{HIF}-2 \alpha$ signaling pathway by degradation of I $\mathrm{KB}$ in IL- $1 \beta$-induced chondrocytes and cartilages in the DMM-induced OA mouse model.

In conclusion, curcumin inhibited the IL- $1 \beta$-induced chondrocyte inflammation by inactivating the NF- $\mathrm{kB} /$ HIF- $2 \alpha$ signaling pathway. This was confirmed by in vivo experiments using a DMM surgically-induced mouse OA model. The results demonstrated that curcumin inhibited inflammation in the articular cartilage, partly by suppressing the activation of NF- $\kappa \mathrm{B} / \mathrm{HIF}-2 \alpha$ in chondrocytes. Curcumin may have the potential to inhibit OA development, partly through suppressing the activation of the NF- $\mathrm{BB} / \mathrm{HIF}-2 \alpha$ pathway. Therefore, curcumin may be a potential therapeutic agent for the treatment of OA.

\section{Acknowledgments}

Funding: This work was funded by grants from the Guangzhou Municipal Health and Family Planning Commission (Grant No. 20191A011018 and 20192A010009 to PW), the Medical Science and Technology Research Foundation of Guangdong (Grant No. A2021335 to PW), the Guangzhou Science and Technology Project (Grant No. 201607010010 and 202102080344 to QM), the National Natural Science Foundation of China (Grant No. 81770291 to SZ), the Guangdong Provincial Natural Science Foundation of China (Grant No. 2018B030311011 to SZ), and the Guangzhou Science and Technology Planning Project (Grant No. 202002030081 to SZ).

\section{Footnote}

Reporting Checklist: The authors have completed the ARRIVE reporting checklist. Available at http://dx.doi. org/10.21037/atm-21-2701
Data Sharing Statement: Available at http://dx.doi. org/10.21037/atm-21-2701

Conflicts of Interest: All authors have completed the ICMJE uniform disclosure form (available at http://dx.doi. org/10.21037/atm-21-2701). The authors have no conflicts of interest to declare.

Etbical Statement: The authors are accountable for all aspects of the work in ensuring that questions related to the accuracy or integrity of any part of the work are appropriately investigated and resolved. This study was approved by the Research Ethics Committee of the Guangzhou Red Cross Hospital, Guangzhou, 510220, China (Approval No. 2019-010-01), in compliance with national or institutional guidelines for the care and use of animals.

Open Access Statement: This is an Open Access article distributed in accordance with the Creative Commons Attribution-NonCommercial-NoDerivs 4.0 International License (CC BY-NC-ND 4.0), which permits the noncommercial replication and distribution of the article with the strict proviso that no changes or edits are made and the original work is properly cited (including links to both the formal publication through the relevant DOI and the license). See: https://creativecommons.org/licenses/by-nc-nd/4.0/.

\section{References}

1. Lawrence RC, Felson DT, Helmick CG, et al. National Arthritis Data Workgroup. Estimates of the prevalence of arthritis and other rheumatic conditions in the United States. Part II. Arthritis Rheum 2008;58:26-35.

2. Allen KD, Golightly YM. Epidemiology of osteoarthritis: state of the evidence, Curr Opin Rheumatol 2015;27:276-83.

3. Vina ER, Kwoh CK. Epidemiology of osteoarthritis: literature update. Curr Opin Rheumatol2018;30:160-7.

4. Bonnet CS, Walsh DA. Osteoarthritis, angiogenesis and inflammation. Rheumatology (Oxford) 2005;44:7-16.

5. Santangelo KS, Nuovo GJ, Bertone AL. In vivo reduction or blockade of interleukin- $1 \beta$ in primary osteoarthritis influences expression of mediators implicated in pathogenesis. Osteoarthritis Cartilage 2012;20:1610-8.

6. Chabane $\mathrm{N}$, Zayed N, Afif $\mathrm{H}$, et al. Histone deacetylase inhibitors suppress interleukin-1beta-induced nitric oxide 
and prostaglandin E2 production in human chondrocytes. Osteoarthritis Cartilage 2008;16:1267-74.

7. Zhang G, Sun Y, Wang Y, et al. MiR-502-5p inhibits IL$1 \beta$-induced chondrocyte injury by targeting TRAF2. Cell Immunol 2016;302:50-7.

8. Eymard F, Pigenet A, Citadelle D, et al. Induction of an inflammatory and prodegradative phenotype in autologous fibroblast-like synoviocytes by the infrapatellar fat pad from patients with knee osteoarthritis. Arthritis Rheumatol 2014;66:2165-74.

9. Chaganti RK, Purdue E, Sculco TP, et al. Elevation of serum tumor necrosis factor $\alpha$ in patients with periprosthetic osteolysis: a case-control study. Clin Orthop Relat Res 2014;472:584-9.

10. Loeser RF, Goldring SR, Scanzello CR, et al. Osteoarthritis: a disease of the joint as an organ. Arthritis Rheum 2012;64:1697-707.

11. Zhang FJ, Luo W, Lei GH. Role of HIF- $1 \alpha$ and HIF-2 $\alpha$ in osteoarthritis. Joint Bone Spine 2015;82:144-7.

12. Henrotin Y, Priem F, Mobasheri A. Curcumin: a new paradigm and therapeutic opportunity for the treatment of osteoarthritis: curcumin for osteoarthritis management. Springerplus 2013;2:56.

13. Asher GN, Spelman K. Clinical utility of curcumin extract. Altern Ther Health Med 2013;19:20-2.

14. Schulze-Tanzil G, Mobasheri A, Sendzik J, et al. Effects of curcumin (diferuloylmethane) on nuclear factor kappaB signaling in interleukin-1beta-stimulated chondrocytes. Ann N Y Acad Sci 2004;1030:578-86.

15. Shakibaei M, John T, Schulze-Tanzil G, et al. Suppression of NF-kappaB activation by curcumin leads to inhibition of expression of cyclo-oxygenase-2 and matrix metalloproteinase-9 in human articular chondrocytes: Implications for the treatment of osteoarthritis. Biochem Pharmacol 2007;73:1434-45.

16. Zhao P, Cheng J, Geng J, et al. Curcumin protects rabbit articular chondrocytes against sodium nitroprusside-induced apoptosis in vitro. Eur J Pharmacol 2018;828:146-53.

17. Chen T, Zhou R, Chen Y, et al. Curcumin ameliorates IL-1 $\beta$-induced apoptosis by activating autophagy and inhibiting the $\mathrm{NF}-\kappa \mathrm{B}$ signaling pathway in rat primary articular chondrocytes. Cell Biol Int 2021:45:976-88.

18. Feng K, Ge Y, Chen Z, et al. Curcumin Inhibits the PERK-eIF2 $\alpha$-CHOP Pathway through Promoting SIRT1 Expression in Oxidative Stress-induced Rat Chondrocytes and Ameliorates Osteoarthritis Progression in a Rat Model. Oxid Med Cell Longev 2019;2019:8574386.

19. Bracken CP, Whitelaw ML, Peet DJ. The hypoxia- inducible factors: key transcriptional regulators of hypoxic responses. Cell Mol Life Sci 2003;60:1376-93.

20. Semenza GL. HIF-1 and human disease: one highly involved factor. Genes Dev 2000;14:1983-91.

21. Murahashi Y, Yano F, Kobayashi H, et al. Intra-articular administration of $\mathrm{I} \kappa \mathrm{B} \alpha$ kinase inhibitor suppresses mouse knee osteoarthritis via downregulation of the NF- $\kappa \mathrm{B} / \mathrm{HIF}$ $2 \alpha$ axis. Sci Rep 2018;8:16475.

22. Gosset M, Berenbaum F, Thirion S, et al. Primary culture and phenotyping of murine chondrocytes. Nat Protoc 2008;3:1253-60.

23. $\mathrm{Pu} \mathrm{Y,} \mathrm{Zhang} \mathrm{H}$, Wang $\mathrm{P}$, et al. Dietary curcumin ameliorates aging-related cerebrovascular dysfunction through the AMPK/uncoupling protein 2 pathway. Cell Physiol Biochem 2013;32:1167-77.

24. Arocho A, Chen B, Ladanyi M, et al. Validation of the 2-DeltaDeltaCt calculation as an alternate method of data analysis for quantitative PCR of BCR-ABL P210 transcripts. Diagn Mol Pathol 2006;15:56-61.

25. Mainil-Varlet P, Van Damme B, Nesic D, et al. A new histology scoring system for the assessment of the quality of human cartilage repair: ICRS II. Am J Sports Med 2010;38:880-90.

26. Wang J, Shi Y, Wang G, et al. The association between interleukin-1 polymorphisms and their protein expression in Chinese Han patients with breast cancer. Mol Genet Genomic Med 2019;7:e804.

27. Ma Z, Wang Y, Piao T, et al. Echinocystic Acid Inhibits IL-1 $\beta$-Induced COX-2 and iNOS Expression in Human Osteoarthritis Chondrocytes. Inflammation 2016;39:543-9.

28. Zheng $W$, Feng Z, You S, et al. Fisetin inhibits IL-1 $\beta$ induced inflammatory response in human osteoarthritis chondrocytes through activating SIRT1 and attenuates the progression of osteoarthritis in mice. Int Immunopharmacol 2017;45:135-47.

29. Csaki C, Mobasheri A, Shakibaei M. Synergistic chondroprotective effects of curcumin and resveratrol in human articular chondrocytes: inhibition of IL-1betainduced NF-kappaB-mediated inflammation and apoptosis. Arthritis Res Ther 2009;11:R165.

30. Xu T, Wang C, Shen J, et al. Ablation of Dnmt3b in chondrocytes suppresses cell maturation during embryonic development. J Cell Biochem 2018;119:5852-63.

31. Wang J, Ma J, Gu JH, et al. Regulation of type II collagen, matrix metalloproteinase-13 and cell proliferation by interleukin- $1 \beta$ is mediated by curcumin via inhibition of NF- $\kappa \mathrm{B}$ signaling in rat chondrocytes. Mol Med Rep 2017;16:1837-45. 
32. Koch B, Baum W, Burmester GR, et al. Prostaglandin $\mathrm{E} 2$, interleukin 1 and gamma interferon production of mononuclear cells of patients with inflammatory and degenerative joint diseases. Z Rheumatol 1989;48:194-9.

33. Li TF, Yukata K, Yin G, et al. BMP-2 induces ATF4 phosphorylation in chondrocytes through a COX-2/PGE2 dependent signaling pathway. Osteoarthritis Cartilage 2014;22:481-9.

34. Li N, Rivéra-Bermúdez MA, Zhang M, et al. LXR modulation blocks prostaglandin E2 production and matrix degradation in cartilage and alleviates pain in a rat osteoarthritis model. Proc Natl Acad Sci U S A 2010;107:3734-9.

35. Kim L, Kim JY. Chondroprotective effect of curcumin and lecithin complex in human chondrocytes stimulated by IL-1 $\beta$ via an anti-inflammatory mechanism. Food Sci Biotechnol 2018;28:547-53.

36. Sumer EU, Qvist P, Tankó LB. Matrix metalloproteinase and aggrecanase generated aggrecan fragments: Implications for the diagnostics and therapeutics of destructive joint diseases. Drug Dev Res 2007;68:1-13.

Cite this article as: Wang P, Ye Y, Yuan W, Tan Y, Zhang S, Meng Q. Curcumin exerts a protective effect on murine knee chondrocytes treated with IL- $1 \beta$ through blocking the NF- $\kappa \mathrm{B} /$ HIF-2 $\alpha$ signaling pathway. Ann Transl Med 2021;9(11):940. doi: $10.21037 /$ atm-21-2701
37. Bai M, Ge L, Chen $\mathrm{H}$, et al. Calcitonin protects rat chondrocytes from IL-1 $\beta$ injury via the $W n t / \beta$-catenin pathway. Exp Ther Med 2019;18:2079-85.

38. Khan NM, Haseeb A, Ansari MY, et al. Dataset of effect of Wogonin, a natural flavonoid, on the viability and activation of NF- $\kappa \mathrm{B}$ and MAPKs in IL-1 $\beta$-stimulated human OA chondrocytes. Data Brief 2017;12:150-5.

39. Chen LF, Greene WC. Shaping the nuclear action of NFkappaB. Nat Rev Mol Cell Biol 2004;5:392-401.

40. Lawrence T. The nuclear factor NF-kappaB pathway in inflammation. Cold Spring Harb Perspect Biol 2009; 1:a001651.

41. Kobayashi H, Chang SH, Mori D, et al. Biphasic regulation of chondrocytes by Rela through induction of anti-apoptotic and catabolic target genes. Nat Commun 2016;7:13336

42. Yang S, Kim J, Ryu JH, et al. Hypoxia-inducible factor2alpha is a catabolic regulator of osteoarthritic cartilage destruction. Nat Med 2010;16:687-93.

(English Language Editor: J. Teoh) 